\title{
Service Quality Bus Rapid Transit Mamminasata Kota Makassar
}

\author{
Shinta Dewi Sugiharti Tikson*
}

Fakultas Ekonomi dan Bisnis, Universitas Hasanuddin Jalan Perintis Kemerdekaan Km. 10, Makassar, Indonesia shintatikson@fe.unhas.ac.id

\section{Syamsinar}

Fakultas Ekonomi dan Bisnis, Universitas Hasanuddin Jalan Perintis Kemerdekaan Km. 10, Makassar, Indonesia inarasis25@gmail.com

\section{Atika}

Fakultas Ekonomi dan Bisnis, Universitas Hasanuddin Jalan Perintis Kemerdekaan Km. 10, Makassar, Indonesia atikabie48@gmail.com

\section{Indri Leighton Silambi}

Fakultas Ekonomi dan Bisnis, Universitas Hasanuddin Jalan Perintis Kemerdekaan Km. 10, Makassar, Indonesia

\section{akashireiton@gmail.com}

Diterima: 08-01-2021 | Disetujui: 07-07-2021 | Dipublikasi: 31-07-2021

\begin{abstract}
ABSTRAK
Melihat realitas saat ini, minat masyarakat menggunakan Bus Rapid Transit (BRT) Mamminasata Makassar menurun sangat drastis. Masalah ini berdampak pada menurunnya pendapatan Perum Damri. Tujuan penelitian ini adalah untuk mengetahui kualitas jasa (service quality) Bus Rapid Transit Mamminasata di Kota Makassar sehingga dapat menambah minat masyarakat dalam menggunakannya. Hasil penelitian menunjukkan gap maksimum dalam penelitian ini sebesar -1.49 yang dapat diartikan bahwa adanya kesenjangan antara persepsi dan harapan responden mengenai jam operasional Bus Rapid Transit Mamminasata. Sebagian besar responden yakni sebanyak 64 orang $(68.1 \%)$ menjawab tidak mengetahui jam operasional BRT Mamminasata sehingga bus sering datang ke halte tidak tepat waktu. Responden memiliki harapan jam operasional (kedatangan dan keberangkatan) BRT Mamminasata tepat waktu dan jelas. Semakin kecil gap (gap mendekati nol atau positif) yang dihasilnya dari hasil perhitungan Servqual, maka semakin baik kualitas jasa perusahaan. Sebaliknya, semakin besar gap yang dihasilkan dari perhitungan Servqual menandakan semakin rendahnya kualitas jasa suatu perusahaan. Dengan demikian, perusahaan jasa seperti Perum Damri yang merupakan perusahaan penyedia moda transportasi Bus Rapid Transit Mamminasata Kota Makassar perlu memprioritaskan perbaikan kualitas jasa berdasarkan hasil perhitungan gap terbesar.
\end{abstract}

Kata Kunci:

Service Quality; Bus Rapid Transit; Mamminasata Makassar; Minat Masyarakat 


\section{ABSTRACT}

People's interest in using the Mamminasata Bus Rapid Transit (BRT) has decreased significantly. This problem has an impact on the decline in Perum Damri's income. The purpose of this study is to determine the service quality of Mamminasata Bus Rapid Transit in Makassar so that it can increase public interest in using this mode of public transportation. Results show that the maximum gap in this study is -1.49 , which means there is a gap between respondents' perceptions and expectations regarding the operational hours of Mamminasata Bus Rapid Transit. Most respondents, as many as 64 people (68.1\%), said they did not know the BRT operational hours and the bus often come late to the bus stop. Respondents' expectation that the BRT operational hours (arrival and departure) would be timely and clear. The smaller the gap (gap close to zero or positive) the better the service quality of the company. Conversely, the larger the gap, the lower the service quality of a company. Thus, service companies such as Perum Damri which is a provider of the Mamminasata Bus Rapid Transit in Makassar need to prioritize in improving service quality based on the results of the largest gap.

Keywords:

Service Quality; Bus Rapid Transit; Mamminasata Makassar; Public Interest 


\section{PENDAHULUAN}

Urbanisasi menjadi salah satu permasalahan kependudukan di Indonesia khususnya di kotakota besar saat ini. Makassar merupakan kota ke-8 terbesar di Indonesia dengan jumlah penduduk mencapai 1,5 juta jiwa dengan luas wilayah 175,77 km² (Badan Pusat Statistik (BPS), 2019). Tingkat kepadatan penduduk akan memberikan pengaruh yang signifikan terhadap kebutuhan transportasi dalam kegiatan keseharian masyarakat. Hal ini ditandai dengan kepemilikan kendaraan pribadi yang mengalami peningkatan.

Di Sulawesi Selatan jumlah kendaraan milik pribadi seperti sepeda motor ataupun mobil mengalami peningkatan sebesar 5 sampai 6 persen (Arbab, 2018). Selanjutnya, (Arbab, 2018) juga memaparkan khusus di Kota Makassar, pada tahun 2016 terdapat 1.425.150 unit kendaraan, di tahun 2017 meningkat menjadi 1.505.835 unit kendaraan, dan di tahun 2018 mencapai 1.563 .608 unit kendaraan. Berdasarkan hasil wawancara bersama Manajer Usaha Perum Damri Cabang Makassar, yang menyatakan bahwa "Jumlah kendaraan yang beroperasi di kota Makassar setiap hari mengalami penambahan 145 unit untuk kendaraan beroda empat, belum termasuk sepeda motor" (Hakim, 2019). Penggunaan transportasi dalam jumlah yang besar dapat memicu kemacetan dan meningkatnya polusi udara.

Salah satu solusi dalam mengatasi kemacetan dan mengurangi polusi udara di Makassar yaitu dengan hadirnya Makassar Smart Transportation berupa Bus Rapid Transit (BRT). Bus Rapid Transit (BRT) telah banyak digunakan di kota- kota besar diseluruh dunia termasuk di Indonesia karena biaya transportasi yang relatif murah. Selain itu, bus dirancang dengan sistem transit yang cepat juga aman dan nyaman bagi penumpang (Ali et al., 2018). Beroperasi sejak 2014, proyek pemerintah pusat tersebut diharapkan menjadi solusi transportasi yang memudahkan mobilisasi masyarakat sekaligus mengatasi kemacetan lalu lintas di Makassar. Akan tetapi, BRT Mamminasata perlahan terancam eksistensinya dengan hadirnya transportasi umum lainnya, seperti angkot dan transportasi online.

Kualitas jasa transportasi Bus Rapid Transit (BRT) menjadi polemik di era digital seperti sekarang. Sebagai transportasi milik pemerintah, BRT diharapkan mampu bersaing dengan transportasi milik swasta seperti transportasi online. Di dalam Peraturan Presiden Nomor 2 Tahun 2015 tentang RPJMN 2015-2019, disebutkan bahwa pembangunan transportasi massal perkotaan menjadi agenda pembangunan nasional (Riawan, 2018). BRT Mamminasata sebagai moda transportasi massal yang beroperasi di Kota Makassar harus mampu bersaing secara kompetitif, namun faktanya minat masyarakat terhadap Bus Rapid Transit (BRT) Mamminasata perlahan mengalami penurunan.

Berdasarkan masalah tersebut, maka peneliti tertarik untuk melihat lebih jauh kendala yang dihadapi Bus Rapid Transit (BRT) Mamminasata sehingga dapat ditawarkan solusi yang mampu memperbaiki sistem operasinya juga dapat meningkatkan minat masyarakat untuk menggunakan BRT 
Mamminasata sebagai moda transportasi utama di Kota Makassar. Oleh karena itu, penelitian ini penting dilakukan untuk mengidentifikasi cara meningkatkan service quality BRT Mamminasata sehingga mampu bersaing dengan moda transportasi umum lainnya. Berdasarkan uraian di atas, maka dapat dirumuskan apakah persepsi dan harapan pelanggan berbeda terhadap service quality Bus Rapid Transit (BRT) Mamminasata Makassar dan apakah terdapat kesenjangan (gap) service quality Bus Rapid Transit (BRT) Mamminasata Makassar.

\section{METODE RISET}

Metode analisis data yang digunakan dalam penelitian ini adalah Servqual. Metode Servqual digunakan untuk mengukur lima dimensi kualitas jasa (service quality). Dari hasil perhitungan Servqual akan memperlihatkan nilai kesenjangan (gap) antara harapan (ekspektasi) konsumen terhadap layanan yang ingin mereka terima dan persepsi konsumen mengenai kualitas jasa yang dirasakan (Zeithaml \& Bitner, 2018).

Pengukuran kualitas jasa dalam model Servqual pertama digunakan dalam penelitian yang dilakukan oleh Parsu Parasuraman, Valarie Zeithaml dan Leonard Berry. Servqual dirancang untuk mengukur harapan dan persepsi pelanggan, serta gap diantara keduanya yang terdapat pada lima dimensi utama service quality yaitu:

Tabel 1. Dimensi Service Quality

\begin{tabular}{ll}
\hline \multicolumn{1}{c}{ Dimensi } & \multicolumn{1}{c}{ Indikator } \\
\hline Tangibles & fasilitas, peralatan, penampilan karyawan, dan sarana komunikasi \\
Empathy & peduli dan perhatian perusahaan kepada pelanggan \\
Reliability & kemampuan untuk melakukan layanan yang dijanjikan dengan andal dan akurat \\
Responsiveness & kesediaan untuk membantu pelanggan dan memberikan layanan yang cepat \\
Assurance & pengetahuan dan kemampuan karyawan dalam meyakinkan pelanggan \\
\hline
\end{tabular}

$$
\text { Sumber: Wilson et al., } 2016
$$

Perhitungan nilai rata-rata persepsi responden dapat dihitung menggunakan persamaan:

$$
\overline{X i}=\frac{\sum x i}{n}
$$

Keterangan :

$\overline{X i} \quad$ : rata-rata jawaban responden untuk pernyataan persepsi atribut ke $-i$

$\sum x i$ : jumlah bobot jawaban pernyataan persepsi atribut ke $-i$

$n \quad$ : jumlah responden

Perhitungan nilai rata-rata harapan responden dapat dihitung menggunakan persamaan:

$$
\overline{Y i}=\frac{\sum y i}{n}
$$

Keterangan :

$\overline{Y i} \quad$ : rata-rata jawaban responden untuk pernyataan harapan atribut ke $-i$ 
$\sum y i$

$n$

: jumlah bobot jawaban pernyataan persepsi atribut ke $-i$

: jumlah responden

Skor Servqual untuk tiap pasang pernyataan bagi masing-masing pelanggan (responden) dapat dihitung dengan menggunakan rumus:

\section{Skor Servqual = Skor Persepsi - Skor Harapan}

\section{HASIL PENELITIAN DAN PEMBAHASAN}

Kuesioner yang disebarkan merupakan survey untuk mengetahui pelayanan jasa Bus Rapid Transit (BRT) Mamminasata di Kota Makassar. Kuesioner disebarkan menggunakan Google Form karena melihat kondisi saat pelaksanaan penelitian dimasa pandemi Covid-19 sehingga tidak memungkinkan untuk peneliti melakukan observasi langsung dan bertemu langsung dengan responden.

Mengingat jumlah populasi yang cukup banyak maka jumlah data yang diambil menggunakan cara sampling. Sampling merupakan bagian dari jumlah dan karakteristik yang dimiliki oleh suatu populasi (Sugiyono, 2013). Tujuan penelitian ini yaitu ingin mengetahui minat masyarakat Kota Makassar dalam menggunakan BRT Mamminasata. Telah dikumpulkan sebanyak 94 responden secara random dengan kriteria: (a) warga Kota Makassar, (b) berdomisili di Kota Makassar, (c) pernah menggunakan BRT Mamminasata minimal satu kali dan/atau (d) familiar dengan moda transportasi BRT Mamminasata.

Jumlah responden dengan jenis kelamin perempuan lebih banyak yakni berjumlah 72 orang (76.6\%) dan responden dengan jenis kelamin laki-laki sebanyak 22 orang (23.4\%). Dari 94 responden terdapat $92.6 \%$ yang berusia 16 - 25 tahun dengan pekerjaan sebagai pelajar/mahasiswa sebesar 85.1\%. Moda transportasi Bus Rapid Transit (BRT) Mamminasata perlu mempertimbangkan faktor demografik pelanggan dan melakukan sosialisasi lebih luas. Terlebih lagi, sebagian besar responden 85.1\% sudah familiar dengan moda transportasi yang ditawarkan Perum Damri tersebut. Selain itu, ada 26.6\% responden pernah menggunakan Bus Rapid Transit (BRT) Mamminasata dengan frekuensi penggunaan BRT paling sedikit 1 - 3 kali sebesar 80\% dan paling banyak 11 kali sebesar 5.7\%.

Untuk 74 responden yang belum pernah menggunakan Bus Rapid Transit (BRT) Mamminasata memiliki beberapa pertimbangan belum mencoba. Sebesar 33.8\% atau 25 reponden menjawab "tertarik tapi belum mencoba", 31.1\% atau 23 responden menjawab "memiliki kendaraan sendiri", 25.7\% atau 19 responden menjawab "tidak/belum familiar dengan BRT", 5.4\% atau 4 responden menjawab "lebih memilih menggunakan transportasi umum lainnya", dan $4.1 \%$ atau 3 responden menjawab "tidak tertarik".

Dengan minimnya minat masyarakat menggunakan BRT Mamminasata berdampak terjadinya kerugian yang dirasakan oleh Perum Damri. Berdasarakan hasil wawanacara dengan Manajer Usaha Perum Damri Makassar menyatakan "Setelah bertahan 5 tahun, kami memutuskan 
untuk menutup sebagian koridor Bus Trans Mamminasata karena tak sanggup menahan kerugian. Pada tahap awal, kami mengoperasikan Koridor 2 yang melayani rute dari mal ke mal di dalam Kota Makassar. Menyusul Koridor 3 rute Terminal Daya-Pallangga, Kabupaten Gowa, dan Koridor 1 Bandara Hasanuddin-Jalan Riburane Makassar. Kemudian Koridor 4 melayani rute Terminal DayaTerminal Maros, dan Koridor 7 Terminal Pallangga-Terminal Pallangga. Semua koridor ditempuh pergi pulang. Kini yang tersisa hanya Koridor 1 dan 3. Dari 30 armada BRT, kami hanya mengoperasikan 10 unit secara bergantian," (Hakim, 2019).

\section{Perhitungan Nilai Servqual}

Nilai persepsi konsumen merupakkan nilai aktual kualitas jasa Bus Rapid Transit (BRT) Mamminasata Kota Makassar. Sedangkan nilai harapan konsumen merupakkan nilai ekspektasi konsumen terhadap kualitas jasa Bus Rapid Transit (BRT) Mamminasata Kota Makassar yang ingin mereka terima. Kualitas jasa dapat diukur melalui seberapa besar perbandingan antara persepsi konsumen atas layanan yang diberikan dengan harapan layanan yang ingin diterima oleh konsumen (Raymond, 2015). Nilai Servqual merupakan perhitungan nilai rata-rata jawaban responden antara persepsi dan harapan konsumen terhadap kualitas jasa Bus Rapid Transit (BRT) Mamminasata Kota Makassar berdasarkan lima dimensi kualitas jasa yakni tangibles, empathy, reliability, responsiveness, dan assurance.

Berdasarkan hasil perhitungan nilai rata-rata gap lima dimensi Servqual pada Tabel 2, dapat diketahui gap maksimum dan gap minimum. Semakin kecil gap (gap mendekati nol atau positif) yang dihasilkan dari perhitungan Servqual, maka semakin baik kualitas jasa perusahaan. Sebaliknya, semakin besar gap yang dihasilkan dari perhitungan Servqual menandakan semakin rendahnya kualitas jasa suatu perusahaan. Pelanggan membentuk ekspektasi tentang nilai dan kepuasan yang akan ditawarkan oleh perusahaan (Kotler \& Armstrong, 2018). Pelanggan yang puas akan membeli lagi produk atau menggunakan kembali jasa dan memberi rekomendasi kepada orang lain. Sedangkan pelanggan yang tidak puas sering beralih ke pesaing dan tidak akan merekomendasikan produk atau jasa kepada orang lain.

Khusus dalam produk jasa, perusahaan harus berhati-hati dalam menetapkan tingkat ekspektasi pelanggan yang tepat (Kotler \& Armstrong, 2018). Jika perusahaan menetapkan ekspektasi terlalu rendah, mungkin dapat memuaskan pelanggan yang membeli tetapi akan gagal menarik pelanggan yang lebih banyak. Namun apabila perusahaan menetapkan ekspektasi terlalu tinggi, pembeli akan kecewa. Nilai pelanggan dan kepuasan pelanggan adalah faktor utama untuk mengembangkan dan mengelola hubungan pelanggan (Kotler \& Armstrong, 2018).

Hasil gap maksimum dalam penelitian ini sebesar -1.49 yang menunjukkan bahwa adanya kesenjangan antara persepsi dan harapan responden mengenai jam operasional Bus Rapid Transit (BRT) Mamminasata. Sebagian besar responden yakni sebanyak 64 orang (68.1\%) menjawab tidak mengetahui jam operasional BRT Mamminasata sehingga bus sering datang ke halte tidak tepat 
Tikson, S.D.S., et al. (2021). Service Quality Bus Rapid Transit Mamminasata ....

waktu. Responden memiliki harapan jam operasional (kedatangan dan keberangkatan) BRT Mamminasata tepat waktu dan jelas. Dengan demikian, perusahaan jasa seperti Perum Damri yang merupakan perusahaan penyedia moda transportasi Bus Rapid Transit (BRT) Mamminasata Kota Makassar perlu memprioritaskan perbaikan kualitas jasa berdasarkan hasil perhitungan gap terbesar. Manajemen kualitas jasa merupakan metode atau cara yang dilakukan perusahaan untuk menciptakan strategi bersaing agar tetap unggul diantara persaingan yang semakin ketat (Tjiptono, 2016). Maka dari itu, perusahaan jasa sepeti Perum Damri perlu menciptakan competitive advantage melalui tingkat kualitas jasa yang diberikan kepada konsumen.

Tabel 2. Nilai Servqual

\begin{tabular}{cccc}
\hline \multirow{2}{*}{ Atribut Pernyataan } & Nilai Persepsi & Nilai Harapan & Gap \\
\cline { 3 - 4 } $\mathbf{1}$ & 1.77 & 2.98 & -1.21 \\
$\mathbf{2}$ & 1.65 & 2.98 & -1.33 \\
$\mathbf{3}$ & 1.80 & 2.96 & -1.16 \\
$\mathbf{4}$ & 1.85 & 2.98 & -1.13 \\
$\mathbf{5}$ & 1.70 & 2.99 & -1.29 \\
$\mathbf{6}$ & 1.48 & 2.97 & -1.49 \\
$\mathbf{7}$ & 1.83 & 2.99 & -1.16 \\
$\mathbf{8}$ & 1.66 & 2.93 & -1.27 \\
$\mathbf{9}$ & 1.84 & 2.95 & -1.11 \\
$\mathbf{1 0}$ & 1.62 & 2.98 & -1.36 \\
$\mathbf{1 1}$ & 1.60 & 3.00 & -1.40 \\
$\mathbf{1 2}$ & 1.80 & 3.00 & -1.20 \\
$\mathbf{1 3}$ & 1.53 & 2.98 & -1.45 \\
$\mathbf{1 4}$ & 1.71 & 3.00 & -1.29 \\
$\mathbf{1 5}$ & 1.54 & 3.00 & -1.46 \\
$\mathbf{1 6}$ & 1.73 & 3.00 & -1.27 \\
$\mathbf{1 7}$ & 1.54 & 3.00 & -1.46 \\
$\mathbf{1 8}$ & 1.59 & 3.00 & -1.41 \\
$\mathbf{1 9}$ & 1.70 & 3.00 & -1.30 \\
$\mathbf{2 0}$ & 1.77 & 2.98 & -1.21 \\
Rata-Rata & 1.69 & 2.98 & -1.30 \\
\hline \multicolumn{4}{c}{ Gap Maksimum } \\
\hline
\end{tabular}

Dalam sebuah wawancara dengan Manajer Usaha Perum Damri Makassar menyatakan: untuk saat ini, jumlah Bus Rapid Transit (BRT) Mamminasata yang beroperasi di Makassar dikurangi karena melihat minat masyarakat yang menurun (Hakim, 2019). Hal ini juga didukung oleh hasil penyebaran survey kepada masyarakat Makassar yang mengungkapkan alasan mereka tidak menggunakan BRT Mamminasata disebabkan tidak pastinya waktu kedatangan bus di halte. Zeithaml dan Bitner (Abbas et al., 2012) memaparkan bahwa perusahaan perlu memperhatikan persepsi konsumen atas kualitas jasa (service quality) yang diterimanya. Pada hakikatnya, service quality menjadi faktor penentu keberhasilan suatu perusahaan karena memiliki keterkaitan langsung dengan kepuasan pelanggan (Kotler \& Keller, 2016). 


\section{KESIMPULAN DAN SARAN}

Minat masyarakat yang menggunakan Bus Rapid Transit (BRT) Mamminasata Makassar menurun sangat drastis. Masalah ini berdampak pada menurunnya pendapatan Perum Damri. Salah satu kunci keberhasilan dan sustainability suatu perusahaan adalah perusahaan yang dapat menciptakan kepuasan pelanggan. Akan tetapi, mendapatkan kepuasan pelanggan terhadap kualitas jasa yang perusahaan berikan tidak mudah karena persepsi dan harapan pelanggan berbeda-beda. Hasil penelitian ini menunjukkan terjadi gap servqual yang besar antara persepsi dan harapan pelanggan terhadap kualitas jasa BRT Mamminasata di Kota Makassar. Gap tersebut terfokus pada masalah jam operasional (kedatangan dan keberangkatan) BRT Mamminasata yang tidak pasti dan tidak jelas. Dengan dilakukannya penelitian ini diharapkan (a) mampu memberikan sumbangsih ide dan solusi dalam mewujudkan peningkatan minat masyarakat terhadap Bus Rapid Transit (BRT) Mamminasata di Kota Makassar, (b) meningkatkan penggunaan moda transportasi publik dalam hal ini adalah Bus Rapid Transit (BRT) Mamminasata Makassar, dan (c) dapat dijadikan referensi atau pedoman bagi Perum Damri dalam strategi peningkatan layanan Bus Rapid Transit (BRT) Mamminasata Makassar.

Adapun keterbatasan riset: (a) waktu penelitian yang sangat singkat dan dalam kondisi pandemi Covid-19 sehingga pengambilan data primer tidak bisa maksimal, (b) untuk penelitian selanjutnya baiknya melakukan survey secara langsung ke lapangan dengan menemui penumpang, juga melakukan observasi langsung terhadap kualitas jasa BRT Mamminasata, dan melakukan wawancara lebih mendalam dengan pihak manajemen Perum Damri.

Dari hasil riset yang telah dilaksanakan dapat kami sarankan:

1. Jadwal kedatangan dan keberangkatan bus harus terjadwal dan tepat waktu. Selain itu, jadwal kedatangan, keberangkatan dan rute bus perlu ditempel di halte dan di dalam bus.

2. Jumlah armada BRT Mamminasata harus lebih banyak dan memiliki rute yang jelas.

3. Halte BRT Mamminasata perlu dibenahi agar penumpang nyaman saat menunggu kedatangan bus.

4. Pihak Perum Damri perlu melakukan sosialisasi yang lebih giat mengenai BRT Mamminasata agar masyarakat Makassar lebih mengenal moda transportasi yang ditawarkan. 


\section{DAFTAR PUSTAKA}

Abbas, B., Ghaleb, A.-A., \& El-Refae, A. (2012). The Relationships between Service Quality, Satisfaction, and Behavioral Intentions of Malaysian Spa Center Customers. International Journal of Business and Social Science, 3(1). www.spamore.com

Ali, I. I., Akmal, M. I., Alfisyahrin, A. L., Indrawan, N. F., \& Tikson, S. D. S. (2018). MAKASSAR SMART TRANSPORTATION: Penerapan Mamminasata Apps dan Mamminasata Card guna optimalisasi Bus Rapid Transit (BRT) Kota Makassar. JBMI (Jurnal Bisnis, Manajemen, Dan Informatika), 14(1), 1-13. https://doi.org/10.26487/jbmi.v14i1.2069

Arbab, A. (2018, November 22). Hingga Oktober 2018, Jumlah Kendaraan di Makassar Capai 1.563 .608 Unit.

CELEBESMEDIA.ID. https://celebesmedia.id/celebes/artikel/1024221118/hingga-oktober-2018-jumlahkendaraan-dimakassar-capai-1-563-608-unit.

Badan Pusat Statistik (BPS). (2019). Luas wilayah menurut kecamatan di Kota Makassar. https://makassarkota.bps.go.id/

Hakim, M. (2019). Pers. comm.

Kotler, P., \& Armstrong. (2018). Principles of Marketing. In pearson (Global Edi). United Kingdom.

Kotler, P., \& Keller, K. L. (2016). Marketing Management. In pearson (Global Edi, Vol. 22). New York. USA.

Raymond, C. P. (2015). Analisis Kualitas Sumber Daya Manusia, Kualitas Pelayanan, Kinerja Organisasi, Kepercayaan Masyarakat dan Kepuasan Masyarakat ( Studi Kasus: Dinas Kependudukan Dan Catatan Sipil Kabupaten Nabire ). Jurnal Teknologi Dan Manajemen Industri, 1(1), 1-8.

Riawan, W. A. (2018). Analisis Pelayanan Bus Rapid Transit Kapasitas Sedang pada Sistem Transportasi Perkotaan [The Service Analysis of Medium Capacity Bus Rapid Transit on the Urban Transportation System]. Warta Penelitian Perhubungan, 30(2), 119-132. https://doi.org/10.25104/warlit.v30i2.688

Sugiyono. (2013). Metode Penilitian Management (Terbaru). Alfabeta. Bandung.

Tjiptono, P. H. \& C. G. (2016). Service, Quality \& Satisfaction . Penerbit Andi Yogyakarta. https://www.researchgate.net/publication/316890418_Service_Quality_Satisfaction

Wilson, A., Zeithaml, V., \& Bitner, M. J. (2016). Services Marketing Integrating Customer Focus Across the Firm. McGraw-Hill Inc.,US.

Zeithaml, V. A., \& Bitner, M. J. (2018). Services Marketing: Integrating Customer Focus Across the Firm. In McGraw-Hill (4th ed., Vol. 51, Issue 3). New York. USA. https://doi.org/10.1016/j.bushor.2008.01.008 
